\title{
A thorough understanding of the mitral apparatus will improve the results of mitral valve repair
}

\author{
Antonio Miceli, $\mathrm{MD}, \mathrm{PhD}$
}

See related article on pages $232-7$.

The mitral valve is a complex structure that requires precisely timed coordination of the left ventricle, papillary muscles, chordae tendineae, leaflets, mitral annulus, and left atrium to achieve a competent valve closure. Failure of any one of these anatomic components may cause mitral regurgitation. Ischemic mitral regurgitation (IMR) is a disease of the ventricle and papillary muscle that leads to valvular dysfunction; by definition, the leaflets and chordal structures usually function normally. IMR is a serious complication after myocardial infarction and is associated with high operative mortality and poor long-term outcome and survival, especially in the setting of acute ischemic events. ${ }^{1}$ The optimal surgical strategy is still debated, as many researchers have reported contradictory results. ${ }^{2}$ This because the pathophysiology of IMR is still poorly understood, and more studies on animal models are required for a better understanding of its mechanism and geometry.

In this issue of the Journal, Timek and colleagues ${ }^{3}$ add new evidence regarding the complex events that occur during acute ischemia in an ovine model of IMR. Specifically, Timek and colleagues ${ }^{3}$ used 28 radiopaque markers implanted in the mitral valve apparatus to evaluate the exact geometric perturbations of the multiheaded papillary muscle tips after occlusion of the circumflex artery for posterolateral ischemia. Mitral regurgitation was simultaneously determined by posterior leaflet tethering near the central edge and relative prolapse of both leaflets near the posterior commissure. These modifications were the expression of a lateral and posterior displacement of posterior papillary muscle away from the midseptal annulus (leaflet tethering) with its heads that moved toward the mitral annulus (leaflet prolapse). Apical displacement of both papillary muscles was never observed, contrasting with previous studies that

\footnotetext{
From the Istituto Clinico Sant' Ambrogio, University and Research Hospitals, Gruppo Ospedaliero SanDonato, Milan, Italy; and the School of Clinical Science, University of Bristol, Bristol, United Kingdom.

Disclosures: Author has nothing to disclose with regard to commercial support.

Received for publication May 4, 2015; accepted for publication May 5, 2015.

Address for reprints: Antonio Miceli, MD, PhD, Istituto Clinico Sant'Ambrogio, University and Research Hospitals, Gruppo Ospedaliero SanDonato, Via Faravelli 16,

Milano, Italy (E-mail: antoniomiceli79@alice.it).

J Thorac Cardiovasc Surg 2015;150:238-9

0022-5223/\$36.00

Copyright (c) 2015 by The American Association for Thoracic Surgery

http://dx.doi.org/10.1016/j.jtcvs.2015.05.015
}

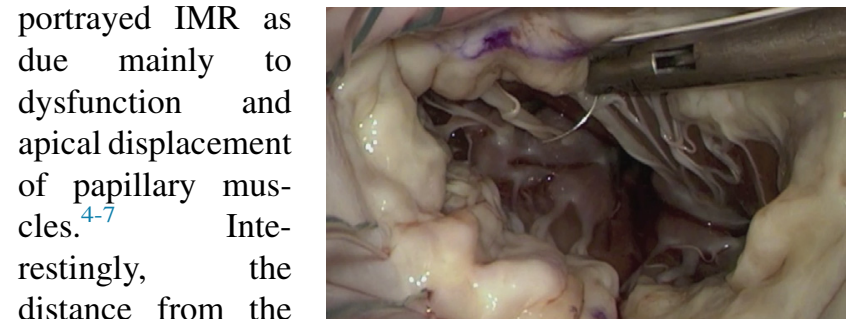
distance from the anterior papillary muscle tips from the annular plane did not change, even though in a previous study Gorman and coworkers ${ }^{8}$ revealed that anterior papillary muscle contracted earlier and more vigorously than before infarction, and its tips moved $1 \mathrm{~mm}$ away from the annular plane. The lack of coordination between the ischemic and nonischemic papillary muscles might modify the leaflets' coaptation, causing IMR. In light of these spatial alterations, Timek and colleagues ${ }^{3}$ suggest intervention on the mitral subvalvular structure, with the aim of relocating the posterior papillary muscle toward the septum. Previously, Langer and associates ${ }^{9}$ demonstrated that an external chord anchored at the right fibrous trigone and passed through the tip of the posterior papillary muscle and left ventricular wall reduced the entity of acute IMR.

Despite detailed information on geometric perturbations of papillary muscles and mitral leaflets, no data are reported on mitral annular and left ventricular changes during acute ischemia. Furthermore, IMR is often a chronic disease, and this study focuses only on an acute scenario. Previously, the Stanford group demonstrated the importance of the septolateral dimension (the distance from the middle of the anterior annulus to the middle of the posterior annulus) of the annulus in the pathophysiology of acute IMR, showing that correcting the septolateral distance alone may abolish acute IMR. ${ }^{10,11}$ Nevertheless, an experimental study of chronic IMR in ovine model revealed similar changes in terms of septal lateral annular dilatation, displacement of the posterior papillary muscle, and apical tethering of the posterior leaflet. ${ }^{12}$ The use of a complete annular ring associated with relocation of the posterior papillary muscle thus may be a promising strategy for correcting IMR and reducing the risk of mitral valve repair failure necessitating late reoperation. A recent metaanalysis comparing outcomes of mitral valve repair versus replacement for IMR noted a higher increase in the risk of recurrence with valve repair. ${ }^{13}$ The high rate of failure could be related to the subvalvular mitral dysfunction. A decade ago, Kron and colleagues ${ }^{14}$ pointed out the importance of 
relocating the posterior papillary muscle as an adjunct to standard annuloplasty to ameliorate the IMR. Recently, Fattouch and coworkers ${ }^{15}$ showed that this technique reduces the tenting area and the coaptation depth with respect to single mitral annuloplasty, with less incidence of recurrent mitral regurgitation at 5 years of follow-up; however, future investigations are required.

All these data suggest that IMR is the result of complex interactions of small changes in the mitral valvular apparatus. Because of the numerous studies conducted by the Stanford group, I would suggest that they design a new study to evaluate how the 6 anatomic components of the mitral valve apparatus-leaflets, chordae tendineae, annulus, papillary muscles, left ventricle, and left atrium-change simultaneously during acute and chronic IMR. A thorough understanding of the mitral apparatus will improve the results of mitral valve repair.

\section{References}

1. Piérard LA, Carabello BA. Ischaemic mitral regurgitation: pathophysiology, outcomes and the conundrum of treatment. Eur Heart J. 2010;31: 2996-3005

2. Lorusso R, Gelsomino S, Vizzardi E, D'Aloia A, De Cicco G, Lucà F, et al. Mitral valve repair or replacement for ischemic mitral regurgitation? The Italian Study on the Treatment of Ischemic Mitral Regurgitation (ISTIMIR). J Thorac Cardiovasc Surg. 2013;145:128-39; discussion 137-8.

3. Timek TA, Lai DT, Bothe W, Liang D, Daughters GT, Ingels NB, et al. Geometric perturbation in multiheaded papillary tip positions associated with acute ovine ischemic mitral regurgitation. J Thorac Cardiovasc Surg. 2015;150:232-7.
4. Gorman RC, McCaughan J, Ratcliffe MB, Gupta KB, Streicher JT, Ferrari VA, et al. Pathogenesis of acute ischemic mitral regurgitation in three dimensions J Thorac Cardiovasc Surg. 1995;109:684-93.

5. Glasson JR, Komeda M, Daughters GT, Bolger AF, Karlsson MO, Foppiano LE, et al. Early systolic mitral leaflet "loitering" during acute ischemic mitral regurgitation. J Thorac Cardiovasc Surg. 1998;116:193-205.

6. Phillips JH, Burch GE, DePasquale NP. The syndrome of papillary muscle dysfunction: its clinical recognition. Ann Intern Med. 1963;59:508-20.

7. Stewart WJ, Sun JP, Mayer E, Lytle BW, Cosgrove DM. Mitral regurgitation with normal leaflets results from apical displacement of coaptation, not annular dilation [abstract]. Circulation. 1994;90:I311.

8. Gorman JH III, Jackson BM, Gorman RC, Kelley ST, Gikakis N, Edmunds LH Jr. Papillary muscle discoordination rather than increased annular area facilitates mitral regurgitation after acute posterior myocardial infarction. Circulation. 1997;96(9 Suppl):II124-7.

9. Langer F, Rodriguez F, Ortiz S, Cheng A, Nguyen TC, Zasio MK, et al. Subvalvular repair: the key to repairing ischemic mitral regurgitation? Circulation. 2005; 112(9 Suppl):I383-9.

10. Lai DT, Timek TA, Dagum P, Green GR, Glasson JR, Daughters GT, et al. The effects of ring annuloplasty on mitral leaflet geometry during acute left ventricular ischemia. J Thorac Cardiovasc Surg. 2000;120:966-75.

11. Timek TA, Lai DT, Tibayan F, Liang D, Daughters GT, Dagum P, et al. Septallateral annular cinching abolishes acute ischemic mitral regurgitation. J Thorac Cardiovasc Surg. 2002; 123:881-8.

12. Tibayan FA, Rodriguez F, Zasio MK, Bailey L, Liang D, Daughters GT, et al Geometric distortions of the mitral valvular-ventricular complex in chronic ischemic mitral regurgitation. Circulation. 2003;108(Suppl 1):II116-21.

13. Dayan V, Soca G, Cura L, Mestres CA. Similar survival after mitral valve replacement or repair for ischemic mitral regurgitation: a meta-analysis. Ann Thorac Surg. 2014;97:758-65.

14. Kron IL, Green GR, Cope JT. Surgical relocation of the posterior papillary muscle in chronic ischemic mitral regurgitation. Ann Thorac Surg. 2002;74:600-1.

15. Fattouch K, Castrovinci S, Murana G, Dioguardi P, Guccione F, Nasso G, et al. Papillary muscle relocation and mitral annuloplasty in ischemic mitral valve regurgitation: midterm results. J Thorac Cardiovasc Surg. 2014;148:1947-50. 